\title{
Culturing the Empathic Health Professional: Challenges and Opportunities
}

\author{
Diana R. Cundell, PhD
}

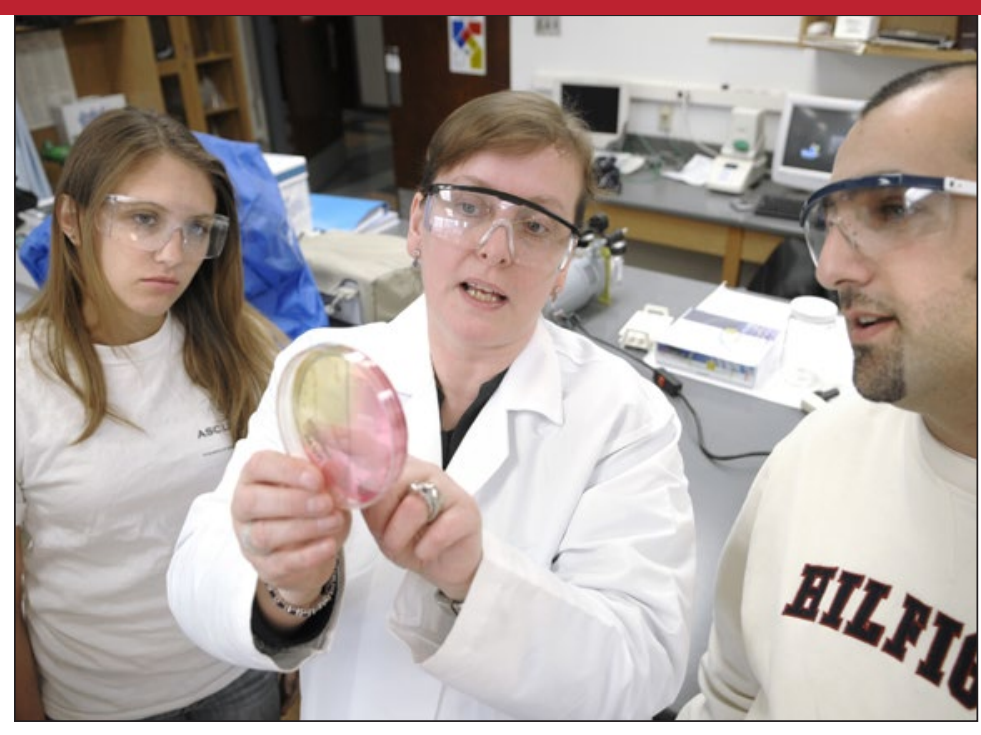

Dr. Cundell (center) pictured here with Jefferson students in Philadelphia.

\section{Abstract}

The selection of our future healthcare professionals is primarily based on a combination of their undergraduate grade point average (GPA) and national examinations, primarily the medical college admissions test (MCAT) or graduate record examination (GRE). Much focus is applied to "getting students ready" to excel in these areas through a combination of heavy individual science curricular components and training in analytical thinking. In contrast, there is little or no emphasis on developing empathy in these students, despite strong evidence that this skill is a requirement for effective patient recovery. In this monograph, I will explore our current understanding of the two types of empathy-affective and cognitive-looking at both brain chemistry and social fabric in maintaining their development. In trying to solve the problem of learning cognitive empathy, I have drawn on more than 20 years of classroom discussion and rubric development with

$66 \overline{\text { Isuggest that }}$ cognitive empathy is a teachable skill. undergraduate health majors, and I suggest that cognitive empathy is a teachable skill. Planting the empathy seed in the undergraduate fertile ground of liberal arts and combining this with role-play simulations in upper-level classes is an optimal start. Continuing the process at the graduate school level in order to counteract erosion and possible exposure to negative behaviors is essential. Finally, the monograph also explores the frequent contradiction between performance on standardized tests and a student's empathic skill, and it ends with some possible holistic strategies for recruitment.

\footnotetext{
Division of Health Professions, College of Science Health and the Liberal Arts, Jefferson (Philadelphia University and Jefferson University), Philadelphia, Pennsylvania.

Address for correspondence: Division of Health Professions, College of Science Health and the Liberal Arts, Jefferson (Philadelphia University and Jefferson University), 4201 Henry Avenue, Philadelphia, PA 19144. E-mail: cundelld@philau.edu 


\section{- Introduction}

Since the mid-1950s, selection of healthcare students has been based on a combination of their grade point average (GPA) and a series of standardized tests to assess cognitive aptitude. ${ }^{1}$ Success on these tests characterizes the future "knowledge workers"-individuals destined for professions that require undergraduate- and often graduate-level training. ${ }^{2}$ Coined by the noted social economist Peter Drucker, knowledge workers were defined as those individuals "that require a good deal of formal education and the ability to acquire and to apply theoretical and analytical knowledge. They require a different approach to work and a different mind-set. Above all, they require a habit of continuous learning." Many universities, including our own, use the phrase "analytical knowledge" and "lifelong learner" as part of good student habits. For students, this means their dream medical career requires a score in the top percentiles of tests, which begin with the high-school scholastic aptitude test (SAT) and culminate with either the medical college admissions test (MCAT) or graduate record examination (GRE). ${ }^{3}$ They are test masters. To gain an edge, those who can afford it will take a series of "test prep" courses and in turn become part of a national industry worth an estimated $\$ 12$ billion. ${ }^{3}$

The next hurdle is that the successful undergraduate healthcare student needs to maintain high grades throughout a series of increasingly content-rich math and science courses, as well as continue to improve their analytical and synthetic skills., ${ }^{4,5}$ A 2013 STEM report observed that by the time an undergraduate pre-healthcare student completes their baccalaureate degree, they have lost between $50 \%$ and $62 \%$ of their classmates, with $35 \%$ switching to other majors. ${ }^{6}$ For those

$6 \longdiv { \text { Knowledge } }$ workers were defined as those individuals 'that require a good deal of formal education and the ability to acquire and to apply theoretical and analytical knowledge.' 99 with a strong GPA, there is one last "academic winnowing" in which those who do not make it across the magical 50th percentile on an MCAT or GRE will have a final change of direction., ${ }^{78}$

Now we come to the missing piece in culturing the healthcare professional: the realization that medicine is more than knowledge acquisition and analysis. Indeed, examples of medical care failures when patients become an industry rather than individuals abound these days and stem from a lack of professionals listening to their patients saying something "isn't right" in their bodies. ${ }^{9}$ This missing element is empathy and involves compassion, ${ }^{9}$ as will be discussed later. Throughout this monograph, it will be apparent that empathy is an essential skill for healthcare practitioners in that it provides job satisfaction and makes patients more likely to get better. ${ }^{9}$ The big question is when and how to teach it and how to assess its acquisition. Before tackling these questions, let us first take a walk in the shoes of the student traveling into a healthcare career to see what shapes them academically as well as prevents their success. 


\section{- The Path to Becoming a Healthcare Professional Is Paved with Standardized Tests}

Becoming a healthcare provider requires a student to overcome three hurdles. The first is to score well on the SAT, which requires analytical thinking in the areas of math, verbal ability, and reading (although the latter is not typically evaluated for undergraduate entrance). ${ }^{10}$ First introduced in 1926, the SAT has undergone many evolutions, primarily to ensure a time-limited test (begun in 1958) and to determine analytical and comprehension abilities (1994). ${ }^{10}$ On the surface, the SAT seems a good measure of academic potential and has been correlated with a student's GPA, ${ }^{11}$ job performance and leadership, ${ }^{12}$ and the likelihood of matriculating from doctoral degrees. ${ }^{13}$

Many critics of the exam have suggested its design operates against female students and those from minorities. ${ }^{14-20}$ Despite SAT revisions, male students appear to outperform their female counterparts by as many as 30 points, particularly in math. ${ }^{14}$ Studies suggest that it may be less a question of female ability than preparation level ${ }^{15}$ and even female versus male personality ${ }^{16}$ and biology. ${ }^{17}$ First, poorly prepared male students are known to be less likely to take the SAT than females, thus throwing a bias in the male sample. ${ }^{15}$ Second, males are more likely than females to guess rather than skip a question ${ }^{16}$ - a strategy that can work against female scores and appears to be hardwired into the brain, according to recent brain-scan data. ${ }^{17}$ Despite SAT issues, more females than males are entering the undergraduate realm, as well as scoring better than male counterparts score in their freshman math courses! ${ }^{18}$ Further studies also suggest that although SAT scores align predominantly with the students' GPA and cognitive abilities, they continue to create a black-white separation that also does not continue when minorities enter higher education. ${ }^{19,20}$

So why not get rid of the SAT? Proponents cite its elimination or use as optional as "bypassing a valid and reliable measure of college readiness." ${ }^{21}$ However, a later meta-analysis by Kuncel and Hezlett argues that although standardized tests are good measures of innate cognitive abilities, other factors will result in an individual's readiness for the workforce. ${ }^{13}$ Admitting based on high-school GPA rather than SAT would allow equally talented students to enter higher education and more than double minority undergraduate students. ${ }^{22}$ SAT retention is also based on pure economics: high schools in which students take the SAT and perform well will receive more financial reward than those that do not (i.e. performance-based merit awards). ${ }^{23}$ 
At the other end of the healthcare student undergraduate experience is the MCAT or GRE. Just as the high-school teacher ensures students acquire knowledge and skill sets to fit them for higher education, so the undergraduate professor begins their mastery. A course load involving a minimum of 10 complex science/math courses is the basic requirement to "get ready" for MCATs, and most students add to this with graduate school requirements, including anatomy and physiology, immunology, and microbiology. MCAT is a good predictor of all parts of the United States Medical Licensing Exams (USMLE) as well as performance in medical school. ${ }^{24}$ However, females typically receive lower scores on the MCAT ${ }^{25}$ and GRE, ${ }^{7}$ as do black or Hispanic students. ${ }^{7,26}$ Similar reasons probably play in as for lower SAT scores, including socioeconomic background, access to a prep course for the test, and family attitudes toward studying or higher education. ${ }^{7,825-27}$ This has led to the removal of the MCAT for some medical schools or the use of a more holistic candidate assessment. ${ }^{27}$ Holistic analysis is beneficial in that it garners students who are less competitive and more likely to be involved in the community of the graduate school, as well as those who value each other's differences ${ }^{27}$ (i.e. it screens for empathy).

\section{- Empathy: What Does It Mean and How Does It Differ Between People?}

Empathy is an essential asset for a healthcare professional and results in patients demonstrating care compliance ${ }^{28}$ and improved health. ${ }^{29,30}$ This is especially important where practitioners are involved in primary care $e^{29,30}$ and in areas of socioeconomic disadvantage. ${ }^{30}$ For healthcare, the empathy that is required is the learned, cognitive form in which the provider can identify with their patients' needs and perceptions of themselves-but at a distance. ${ }^{9}$ The "empathy" that is in common usage is affective empathy, and interestingly although they involve different parts of the brain, ${ }^{9,31-33}$ they are both required for positive social interactions. ${ }^{32,33}$ Brain studies have suggested we cannot be logical and compassionate simultaneously, ${ }^{34}$ a feature that is described in cognitive empathy as "decentering" or crossing into and back from the patient, ${ }^{9}$ thus allowing a flux of empathy and logic to occur. ${ }^{9}$

Much of the usage of cognitive empathy in healthcare grew out of the field of psychotherapy in which the analyst identified with the patient and became effectively "one with them" in order to provide effective counseling and treatment. ${ }^{35}$ The use of cognitive rather than affective empathy, it was argued, would also prevent "provider burnout" from the barrage of emotional encounters elicited by patient contact. ${ }^{9}$ If medicine were merely a rule-based set of disciplines, many types of conditions could ostensibly be reliably diagnosed and managed by online apps. ${ }^{36}$

Since empathy is central to effective healthcare, how do we screen for it in our student candidates? The Cliffs' notes answer is that if standardized tests favor 
males, empathy assessments point to females. ${ }^{28,37,38}$ One reason may stem from differential biology. ${ }^{31,32}$ Females show greater ability to read nonverbal and facial cues and are more likely to be involved in social behaviors such as volunteering. ${ }^{31}$ One study has suggested that early lack of empathy in 6- to 8-year old males may also be due to high fetal testosterone levels. ${ }^{37}$ Support for female superiority in empathy has also come from results of the Jefferson Scale of Physician Empathy test (JSPE). ${ }^{38}$ This test is intriguing, since it demonstrates a direct correlation with success in clinical care but has no relationship to either MCAT or USMLE scores..$^{38}$ Using the JSPE to assess undergraduate nursing students produced similar data; women scored higher than their male counterparts, and older students were more empathic than younger ones. ${ }^{39}$ Older female students tend to score better on the MCAT and are less likely to have difficulty in medical school, ${ }^{25}$ adding another variable to admissions decisions. Finally, it may even be that males don't possess less empathy; they are just less "emotionally reactive" and are as likely to want to help someone in need than their female counterparts. ${ }^{40}$ Emotional reactivity is also greater if a healthcare student ${ }^{41,42}$ or provider ${ }^{43,44}$ is of the same ethnic group as their patient. Brain imaging suggests the reactions may be unconscious and driven by a "group membership" mentality rather than actual negativity/racism. ${ }^{41-44}$ This type of bias can be unlearned through the employment of a "perspective taking task." ${ }^{42}$

Empathy clearly differs between individuals, and the amount we demonstrate has its own limitations. Since we already choose intelligent, analytical people for healthcare and can successfully train them to understand complex and taxing topics, why not add empathy to this list? Which method to use is more complex: one class or several, undergraduate or graduate school? A logical approach might be to consider empathy as a language, which would make older children and young adults the fastest learners. ${ }^{45}$ High-school/ undergraduate students would therefore be the fastest learners. Given the diversity of high-school experiences, undergraduate degrees might be the better of these two options and allow for a seamless learning approach by embedding it in a series of classes with a culminating set of experiences.

\section{- The Language of Medicine Is Empathy: Where Do We Learn It and How Can We Get an 'A'?}

Since 1953, educators have promoted the idea that the well-prepared pre-health student should obtain a "Baccalaureate education that encompasses broad study 
in the natural and the social sciences and in the humanities." ${ }^{36}$ Liberal arts institutions encompass this model and stress cultural sensitivity, problem solving rather than memorizing, intellectual curiosity, and a willingness to collaborate rather than compete. ${ }^{46}$ The integrated curriculum immediately lends itself to reinforcing the concepts of empathy, which after all is the ability to relate to and understand another human being, no matter how different they are from ourselves. Liberal arts institutions also provide a seamless learning environment where discussion produces creative and novel solutions. ${ }^{46-48}$ Trans-disciplinary approaches to learning appeal to female and minority students who are more likely to flourish under its educational umbrella. ${ }^{47,48}$ In turn, an institution with a student population that is a melting pot of economic and racial blends improves empathic development. ${ }^{46-48}$ Liberal arts institutions, like our own, view science as a borderless discipline, blending into history, social, and cultural attitudes. ${ }^{48}$ Students realize there is more to science than just understanding the information in a textbook! Sensitivity to cultural belief systems is essential to the success of all health programs. ${ }^{49} \mathrm{~A}$ recent article in Science commented: "Public health interventions often fail because of a lack of attention to their social, cultural, and historical contexts and engagement with the people they are designed to benefit." ${ }^{49}$ Graduates from liberal arts institutions have traditionally been more successful in a variety of scientific disciplines ${ }^{48}$ and obtain preferential acceptance to medical school. ${ }^{46}$ Pre-nursing curricula are embedding liberal arts skills of communication and cultural sensitivity into their required courses, as well as encouraging students to take courses involving humanities, ethics, and sociology, to name but a few. ${ }^{50}$

Our final piece in the puzzle is developing and nurturing effective patientprovider communication. ${ }^{51-53}$ During graduate school, the assessment of students' ability involves critiqued "standardized" or "peer role-play" exercises. ${ }^{51-54}$ Peer role-playing is considered optimal, since it "may allow students to personally experience patients' concerns, whereas standardized patients have more potential with respect to training specific communication skills." ${ }^{1,52}$ "Despite its relatively low fidelity, role-playing can reap substantial benefits, especially in the realms of team training and/or change in attitudes. ${ }^{34}$ At the undergraduate level, peer role-playing is also highly beneficial, ${ }^{54,55}$ especially for females. ${ }^{54}$ As a biology professor in a liberal arts institution, I have observed firsthand the positive influence of role-play on undergraduate cognitive empathy development. Since 1997, junior pre-medical studies and physician assistant students have role-played being a healthcare professional and a patient. ${ }^{48}$ Many have expressed the importance of this as an early experience that increased their comfort level with "real patients" later on. ${ }^{48}$

Since one critique of role-playing is its lack of empiricism,,${ }^{52-55}$ a class-directed grading rubric for peer observers in the histology class was recently created. Several things immediately emerged. Some students, particularly reserved and 
male students, were "uncomfortable about acting," which led to a debate on how to demonstrate professional caring. This is in keeping with other studies on personality-associated comfort with role-play ${ }^{52-55}$ and male emotional reactivity. ${ }^{40}$ Incorporation of an introductory PowerPoint describing cognitive empathy as a learned skill as well as formalization of behaviors ("dos and don'ts" of patient communication) also eased nervousness, as has been previously suggested. ${ }^{55}$ "Dos" included the importance of body language (eye contact, tone of voice, mirroring). ${ }^{53-55}$ "Don'ts" for the provider included making predictions of the condition before the test results came back, using the term "abnormal," and predicting the disease progression (Cundell DR, Pierce J, unpublished data). Like other investigators, an open-ended survey was used to determine the benefits of role-play in fostering empathy. ${ }^{52-54}$ Students enrolled in histology either currently or within the past three years were surveyed and asked to give gender and major as their only descriptors (Cundell DR, Pierce J, unpublished data). To improve compliance, the survey construct was minimalist, with 10 statements being scored on a $0-10$ scale, where 10 was complete agreement (Cundell DR, Pierce J, unpublished data). Analysis of 66 questionnaires, which represented a return sample of $82.5 \%$ of the 80 sent out, suggested the exercise was effective in at least 7/10 areas surveyed (Cundell DR, Pierce J, unpublished data). Students felt the experience was highly enriching, creative, successful in clarifying the disease process, improved their knowledge depth, developed professionalism, improved presentation skills, and developed empathic ability (mean scores of 8.83, 8.79, $8.95,8.91,8.65,8.62$, and 8.80 , out of 10 , respectively; Cundell DR, Pierce J, unpublished data). The exercise was rated as rigorous, requiring a lot of time to prepare (5.48/10), and an extensive literature review (6.47/10; Cundell DR, Pierce J, unpublished data). Finally, the students remained split on whether clear directives had been received (mean value of $7.27 \pm 3.2$; Cundell DR, Pierce J, unpublished data).

Physician assistant students $(\mathrm{n}=39)$ gave significantly higher ratings for the role-play being creative $(\mathrm{p}<0.05)$ and developing professionalism $(\mathrm{p}<0.05)$ than pre-medical studies students did ( $\mathrm{n}=27$; Cundell DR, Pierce J, unpublished data). Females gave significantly higher ratings for the exercise developing creativity, professionalism, and empathy ( $\mathrm{p}<0.05$; Cundell DR, Pierce J, unpublished data). One student summed up empathy (supportiveness) as:

I feel like by offering all the possible treatments, explaining to the patients that they can contact you if needed, and by having an actual sit down conversation with a patient is supportiveness. The most recent doctor I shadowed explained how just spending a little extra time with each patient helps create a relationship with them and make them more comfortable. She told me that a lot of times this backs up her appointments and that so many doctors don't do that today. (Male Pre-Medical Studies student). 
Undergraduate (Cundell DR, Pierce J, unpublished data) ${ }^{55}$ and graduate ${ }^{52,53}$ responses to peer role-play experiences are very similar. If nothing else, these studies suggest that at both levels of professional training, this exercise is successful in initiating and developing empathy, which should be a continuous process.

\section{- Conclusions and Further Directions}

Students planning a healthcare career focus on grades and standardized tests. ${ }^{3-8,14-20}$ Ironically, successful matriculants, including females and minorities, often come from liberal arts institutions. ${ }^{46-49}$ Mixing with diverse individuals stimulates discussion, expands cultural sensitivity, and creates more practical solutions. ${ }^{56,57}$ Overlaying a curriculum blending biological and social sciences generates a socially and culturally aware graduate (Cundell DR, Pierce J, unpublished data). ${ }^{46-49}$ Add in early cognitive empathy training through role-playing (Cundell DR, Pierce J, unpublished data) $)^{52,53}$ and you have the recipe for a successful healthcare practitioner. ${ }^{46-49}$ Cognitive empathy can be learned (Cundell DR, Pierce J, unpublished data), ${ }^{46-49,58}$ but the bad news is that it needs continuous reinforcement. ${ }^{59,60}$ Studies of junior medical students suggest that their empathy erodes just as they enter the clinical setting. ${ }^{59,60}$ As one physician, describing medical school, put it: "Most of us came from relatively comfortable backgrounds, spent summers working in a lab and

66 Studies of junior medical students suggest that their empathy erodes just as they enter the clinical setting.99 had parents heavily vested in our education. Two of us, while not related, even shared a relatively uncommon last name. The few classmates from underrepresented groups in medicine-African-Americans, Latinos and Native Americansstood out." ${ }^{\prime 2}$ Since empathy skills erode, it makes sense to front load their development at the undergraduate level through holistic curricular strategies. We also can use the JSPE to identify and select undergraduate students who possess these early skills. ${ }^{39}$

The healthcare curriculum of the future will need to shift focus from knowledge acquisition and prioritize cognitive empathy. As Dr. Helen Riess observes, "Perhaps medical schools could begin by valuing both humanistic skills and academic skills when selecting medical students. Because studies show that empathy is challenged during medical training, medical schools could welcome the opportunity to cultivate virtue. As we have seen, virtue can be learned or lost. Given this choice, it should be an easy decision for medical schools to embrace teaching virtue, laying the foundation on which residency programs and continuing medical education programs fostering humane care can be built. Empathy must be reinforced and strengthened with targeted training, rather than allowing it to erode and be replaced with cynicism. Our patients, our families, and we all need much more than that." ${ }^{3}$.II 


\section{- Acknowledgments}

I would like to thank Dr. John Pierce for his assistance in the processing and statistical analysis of the data on role-playing.

\section{- Author Disclosure Statement}

No competing financial interests exist.

\section{- References}

1. Kinkel NR, Hezlett SA, Ones DS. Academic performance, career potential, creativity, and job performance: can one construct predict them all? Journal of Personality and Social Psychology. 2004. 86: 148-161.

2. Drucker PF. The age of social transformation. The Atlantic Monthly. 1994. 274: 53-80.

3. Teehan S. New SAT paying off for the prep test industry. Wall Street Journal. March 5, 2016. Available at https://www.bostonglobe.com/ business/2016/03/04/new-sat-paying-off-for-test-prep-industry/ blQeQKoSzlyAksN9N9463K/story.html (last accessed September 8, 2017).

4. Jenkins A. Employers more interested in critical thinking than in college major. AAC\&U Report. April 10, 2013. Available at https://www.aacu.org/press/ press-releases/employers-more-interested-critical-thinking-andproblem-solving-college-major (last accessed September 8, 2017).

5. Ghazivakili Z, Norouzinia R, Panahi F, et al. The role of critical thinking skills and learning styles of university students in their academic performance. Journal of Advances in Medical Education and Professionalism. 2014. 2: 95-102.

6. Chen X, Soldner M. STEM attrition: college students paths into and out of STEM fields. November 2013. Available at https://nces.ed.gov/ pubs2014/2014001rev.pdf (last accessed September 8, 2017).

7. Bleske-Rechek A, Browne K. Trends in GRE scores and graduate enrollments in gender and ethnicity. Intelligence. 2014. 46: 25-34.

8. The MCAT@ 2015 Year at a Glance. Available at https://www.aamc.org/down load/454206/data/mcatatglance2015.pdf (last accessed September 8, 2017).

9. Jeffrey D. Empathy, sympathy and compassion in healthcare: Is there a problem? Is there a difference? Does it matter? Journal of the Royal Society of Medicine. 2016. 109: 446-452.

10. Lawrence I, Rigol GW, Van Essen T, et al. Research Report No. 2003-3: A historical perspective on the content of the SAT. College Entrance Examination Board. Available at http://www.ets.org/Media/Research/pdf/ RR-03-10-Lawrence.pdf (last accessed September 5, 2017).

11. Cullen MJ, Hardison CM, Sackett PR. Using SAT-grade and ability-job performance relationships to test predictions derived from stereotype threat theory. Journal of Applied Psychology. 2004. 89: 220-230. 
12. Lubinski D. Exceptional cognitive ability: the phenotype. Behavioral Genetics. 2009. 39: 350-358.

13. Kuncel SR, Hezlett SA. Fact and fiction in cognitive ability for admissions and hiring decisions. Current Directions in Psychological Science. 2010. 19: 339-345.

14. Perry MJ. 2016 SAT test results confirm pattern that's persisted for 50 yearshigh school boys are better at math than girls. AEIdeas. September 27, 2016. Available at http://www.aei.org/publication/2016-sat-test-results-confirmpattern-thats-persisted-for-45-years-high-school-boys-are-better-at-maththan-girls/ (last accessed September 7, 2017).

15. Morrison W, Finlay G. Actually SAT results don't confirm that boys are better at math than girls. AIdeas. October 16, 2016. Available at http://www.aei. org/publication/sat-results-dont-confirm-boys-better-at-math-than-girls/ (last accessed September, 7 2017).

16. Byrnes, J, Miller D, Schafer W. Gender differences in risk taking: a metaanalysis. Psychological Bulletin. 1999. 125: 367-383.

17. Price M. Study finds some significant differences in the brains of men and women. Science. April 11, 2017. Available at http://www.sciencemag.org/ news/2017/04/study-finds-some-significant-differences-brains-men-andwomen (last accessed September 8, 2017).

18. Mattern KD, Patterson BF, Kobrin JL. The validity of SAT scores in predicting first-year mathematics and English grades. (No. 1). College Board 202. Available at https://research.collegeboard.org/sites/de fault/files/info2go/2012/11/infotogo-2012 (last accessed September 8, 2017).

19. Young JW, Kobrin JL. Differential validity, differential prediction and college admissions testing: a comprehensive review and analysis. College Board Research Report 2001-6, 2001. Available at http://files.eric.ed.gov/ full text/ED562661.pdf (last accessed September 7, 2017).

20. Coyle T, Snyder A, Pillow D, et al. SAT predicts GPA better for high ability subjects: implications for Spearman's Law of Diminishing Returns. Personality and Individual Differences. 2011. 50: 470-474.

21. Jurik K. Test optional sound to be too good to be true because it is. U.S. News. December 24, 2012. Available at https://www.usnews.com/opinion/ articles/2012/12/24/colleges-must-keep-the-sat-requirement (last accessed September 7, 2017).

22. Jaschik S. The impact of dropping the SAT. Inside Higher Ed. March 26, 2009. Available at https://www.insidehighered.com/news/2009/03/26/sat (last accessed September 7, 2017).

23. Edwards AT, Pula JJ. Back to high school: a teacher educator's hands-on en counter with the pressures of high-stakes testing. Delta Kappa Gamma Bulletin. 2011. 11-14.

24. Callahan CA, Hojat M, Veloski J, et al. The predictive validity of three versions of the MCAT in relation to performance in medical school, residency and licensing examinations: a longitudinal study of 36 classes of Jefferson Medical College. Academic Medicine. 2010. 85: 980-987. 
25. Haist SA, Wilson JF, Elam CL, et al. The effect of gender and age on medical school performance: an important interaction. Advances in Health Sciences Education. 2000. 5: 197-200.

26. Dwight D, Dorsey JK, Franks RD, et al. Do racial and ethnic group differences in performance on the MCAT reflect test bias? Academic Medicine. 2013. 88: 593-602.

27. Chen PW. The changing face of medical school admissions. May 2, 2013. Available at https://well.blogs.nytimes.com/2013/05/02/the-changingface-of-medical-school-admissions/ (last accessed September 7, 2017).

28. Hojat M, Mangione S, Gonnella JS, et al. Empathy in medical education and patient care. Academic Medicine. 2001. 76: 669-671.

29. Deerksen F, Bensing J, Lagro-Janssen A. Effectiveness of empathy in general practice: a systematic review. British Journal General Practice. 2013. 63: $76-84$.

30. Mercer SW, Neumann M, Wirtz M, et al. General practitioner empathy, patient enablement and patient-reported outcomes in primary care in an area of high socio-economic deprivation in Scotland-a pilot prospective study using structural equation modeling. Patient Education Counsel. 2008. 73: $240-245$.

31. Christov-Moore L, Simpson EA, Coudé G, et al. Empathy: gender effects in brain and behavior. Neuroscience and Biobehavioral Reviews. 2014. 46: 604627.

32. Eres R, Decety J, Molenbergh LW. Individual differences in local gray matter density are associated with differences in affective and cognitive empathy. NeuroImage. 2015. 117: 305-310.

33. Apps MAJ, Lockwood PL, Balsters JH. The role of the midcingulate cortex in monitoring others' decisions. Frontiers in Neuroscience. 2013. 7: 251.

34. Dvorsky G. Our brains can be logical and compassionate just not at the same time. Neuroscience. November 1, 2012. Available at http://io9. gizmodo.com/5957003/our-brains-can-be-logical-and-compassionate---just-not-at-the-same-time (last accessed September 12, 2017).

35. Joseph S, Murphy D. Person-centered approach, positive psychology, and relational helping. Journal of Humanistic Psychology. 2012. 53: 26-51.

36. Landro L. How apps can help manage chronic diseases. Wall Street Journal. June 25, 2017. Available at https://www.wsj.com/articles/how-apps-canhelp-manage-chronic-diseases-1498443120 (last accessed September 5, 2017).

37. Chapman E, Baron-Cohen S, Aueyeung B, et al. Fetal testosterone and empathy: evidence from the Empathy Quotient (EQ) and the "Reading the Eyes in the Mind" test. Social Neuroscience. 2006. 1:135-148.

38. Hojat M, Mangione S, Nasca TJ, et al. The Jefferson Scale of Physician Empathy: development and preliminary psychometric data. Educational and Psychological Measurement. 2001. 61: 349-365.

39. Fields SK, Mahan P, Tillman P, et al. Measuring empathy in healthcare profession students using the Jefferson Scale of Physician Empathy: health 
provider-student version. Journal of Interprofessional Care. 2011. 25: 287293.

40. Rucker L, Branch B, Doan T. Are gender differences in empathy due to differences in emotional reactivity? Psychology. 2011. 2: 574-578.

41. Kaseweter KA, Drwecki BB, Prkachin KM. Racial differences in pain treatment and empathy in a Canadian sample. Pain Research and Management: The Journal of the Canadian Pain Society. 2012, 17: 381-384.

42. Drwecki BB, Moore CF, Ward SE, et al. Reducing racial disparities in pain treatment: the role of empathy and perspective-taking. Pain. 2011. 152: 1001-1006.

43. Xu X, Zuo X, Wang X, Han S. Do you feel my pain? Racial group modulates empathic neural responses. The Journal of Neuroscience. 2009. 29: 8525-8529.

44. Contreras-Huerta L, Baker KS, Reynolds KJ, et al. Racial bias in neuropathic responses to pain. PLoS One. 2013. 8: e84001.

45. Mũnoz C, ed. Age and the Rate of Foreign Language Learning. Tonawanda, NY: Multilingual Matters, 2006.

46. Stratton TD, Elam CL, McGrath MG. A Liberal arts education as preparation for medical school. Academic Medicine. 2003. 78: S59-S61.

47. Seifert SA, Goodman KM, Lindsay N, et al. The effects of liberal arts experiences on liberal arts outcomes. Research in Higher Education. 2008. 49: 107-125.

48. Cundell DR. Science is a borderless discipline. Thought and Action. Fall 2006. Available at http://www.nea.org/assets/img/PubThoughtAndAction/ TAA_06_06.pdf (last accessed September 14, 2017).

49. Hermann, ML. Linking liberal and professional learning in nursing education. AAC\&U. Fall 2004. Available at https://www.aacu.org/publications-re search/periodicals/linking-liberal-and-professional-learning-nursingeducation (last accessed September 14, 2017).

50. Halliday JEB, Hampson K, Hanley N, et al. Driving improvements in emerging disease surveillance through locally relevant capacity strengthening. Science. 2017. 357: 146-148.

51. Duffy DF, Gordon GH, Whelan G, et al. Assessing competence in communication and interpersonal skills: the Kalamazoo II report. Academic Medicine. 2004. 79: 495-507.

52. Bosse HM, Nickel M, Huwendiek S, et al. Peer role-play and standardized patients in communication training: a comparative study on the student perspective on acceptability, realism and perceived effect. BMC Medical Education. 2010. 10: 27.

53. Taj J, Molloy E, Haines T, et al. Same-level peer-assisted learning in medical clinical placements: a narrative systematic review. Medical Education. 2016. 50: 469-484.

54. Galloway SJ. Simulation techniques to bridge the gap between novice and competent healthcare professionals. OJIN: The Online Journal of Issues in Nursing. 2009. 14: Manuscript 3. 
55. Nestel B, Tierney T. Role play for medical students learning about communication: guidelines for maximizing benefits. BMC Medical Education. 2007. 7: 3.

56. McLeod PL, Lobel SA, Cox TH. Ethnic diversity and creativity in small groups. Small Group Research. 1996. 27: 248-264.

57. Hurtado S. Benefits and challenges of diversity in academic settings. Women in Science and Engineering Leadership Institute. Available at https://wiseli. engr.wisc.edu/docs/Benefits_Challenges.pdf (last accessed September 12, 2017).

58. Riess H. Can empathy be learned? Medscape. September 1, 2013. Available at http://www.medscape.com/viewarticle/778463_4 (last accessed September 12, 2017).

59. Hojat M, Vergare MJ, Maxwell K, et al. The devil is in the third year: a longitudinal study of erosion of empathy in medical school. Academic Medicine. 2009. 84: 1182-1191.

60. Rosenthal S, Howard B, Schlussel YR, et al. Humanism at heart. Preserving empathy in third-year medical students. Academic Medicine. 2011. 86: 350-358. 